Thorax (1974), 29, 505.

\title{
Fractional carbon monoxide uptake in an employed population
}

\author{
JAMES H. STEBBINGS, Jr ${ }^{1}$ \\ Division of Epidemiology, School of Public Health, University of Minnesota, Minneapolis, \\ Minnesota 55455, USA
}

\begin{abstract}
Stebbings, J. H. (1974). Thorax, 29, 505-510. Fractional carbon monoxide uptake in an employed population. The fractional carbon monoxide uptake in 913 New York City transit workers was studied. A prediction equation for white males, based on nonsmokers, was obtained: fractional CO uptake $=0.58032-0.00204 \times$ age $+0.0004 \times$ weight (kilograms). Weight was the index of body size most strongly correlated with the fractional $\mathrm{CO}$ uptake. Decline in function with age by amount of tobacco smoked is described. A correction factor for respiration, based on results from 581 workers with two or more tests, was calculated: $-0.123654 \times$ (standard tidal volume-observed tidal volume). Tidal volume was the most important contributor to individual variability of the fractional $\mathrm{CO}$ uptake, and minute volume or respiration rate do not add significantly to it. For epidemiological or screening uses, prediction equations are given for the fractional $\mathrm{CO}$ uptake corrected to 0.51 . tidal volume. Respiration variables explain only $1.5 \%$ of individual variability, and individual variability over a mean period of 16.6 months was much larger (an individual standard error of 0.07 ) than the unexplained population variability (a population standard error of 0.01-0.02); thus the usefulness of the fractional $\mathrm{CO}$ uptake as a test of respiratory function is in doubt.
\end{abstract}

The fractional carbon monoxide uptake has been suggested as a useful index of pulmonary diffusing capacity in clinical evaluations, in respiratory screening programmes, and in epidemiological studies (Bates, Macklem, and Christie, 1971; Lacoste, 1971, 1972). The study reported on here was designed to evaluate this, to establish normal values, and to determine the effects of cigarette smoking.

\section{SUBJECTS}

A survey of the prevalence of chronic respiratory disease was carried out in New York City Transit Authority workers between November 1961 and August 1963. A total of 7,974 workers with job titles of motorman, surface line operator, and surface line dispatcher were studied. Details of the survey and results are given by Densen, Jones, Bass, and Breuer (1967), Densen et al. (1969), and Stebbings $(1972 ; 1973)$.

From the workers surveyed approximately 2,000 were selected for a five-year follow-up study which was carried out between June 1964 and June 1969. Criteria for selection for the follow-up study were complex and depended upon the smoking histories, ages, one-second forced expiratory volumes, and symptoms of the indivi-

${ }^{1}$ Current address: Epidemiology Branch, Human Studies Laboratory, National Environmental Research Center, Environmental Protection Agency, Research Triangle Park, North Carolina 27711. duals (Densen, Jones, and Bass, 1965). The majority of individuals in the follow-up study may be considered as a random sample of the surveyed transit workers; among the remainder there was an excess of both nonsmokers and heavy smokers, and among smokers there was an excess of individuals with either high or low one-second forced expiratory volumes or severe or absent respiratory symptoms. An analysis of the effect of lack of random selection of the follow-up population upon the results of this paper will be presented below.

The fractional carbon monoxide uptake was measured at only one of the three clinic sites in Brooklyn and Manhattan utilized in the follow-up study. A total of 913 individuals had at least one fractional CO uptake test, but it is not known what fraction of the respondents attending the one clinic this represents. For all three clinics combined, $89.8 \%$ of the defined follow-up population received at least one examination. The analyses presented in this paper are based on these 913 individuals, or upon a subset of 581 of the 913 who had two or more tests of their fractional $\mathrm{CO}$ uptake during the five-year study period.

METHODS Respondents were interviewed and examined in most cases immediately following their annual (if over 50 years of age) or biannual (if younger) Transit Authority physical examination. An intensive effort was made to induce retirees, ex-employees, and those not scheduled 
for a routine physical examination in that year to make a special appointment for their follow-up examination. The questionnaire covered respiratory symptoms and smoking habits. Routine spirometry was done.

For determination of the fractional CO uptake (FUCO) the subject was seated and allowed to breathe room air for two minutes with mouthpiece and noseclips in place. Then for three minutes the subject breathed a mixture of air and approximately $0.1 \%$ carbon monoxide. Expired air was collected for the following two minutes, while the technician counted and recorded respirations per minute. The collected air was immediately analysed in a N.V. Godart infrared $\mathrm{CO}$ analyser; the volume used in analysis was recorded and added to the volume remaining in the collection bag, which was measured in a Parkinson Cowan type CD1 portable spirometer. The volume measured was corrected to BTPS. The infrared meter was calibrated daily with known gas mixtures. The minute ventilation ( $\dot{\mathrm{V} E}$ ) was calculated, and divided by the respiration rate to give the tidal volume (VT).

The fractional $\mathrm{CO}$ uptake was calculated as:

$$
\text { FUCo }=\frac{\text { Finco }- \text { Fexco }}{\text { Finco }}
$$

No allowance was made for the small difference between inspired and expired volumes.

CHARACTERISTICS OF SUBJECTS The age range of subjects was from 25 to 70 years of age, the mean age 49.0 years. Of the 913 subjects, $30 \cdot 12 \%$ were Negroes; the mean age of these was 43.7 years. The mean standing height of the subjects was $176.72 \mathrm{~cm}$, the mean weight $82.36 \mathrm{~kg}$. The mean value for the fractional $\mathrm{CO}$ uptake was 0.486 , for the tidal volume 0.4201 ., for the minute volume $7.47 \mathrm{l}$, and for the respiratory rate $17 \cdot 7$ per minute.

\section{RESULTS}

EFFECT OF VENTILATION Minute ventilation $(\dot{V} E)$, tidal volume (VT), and respiratory rate (RR) affect the diffusing capacity of the lung (Anderson and Shephard, 1968). These factors, within the range of values found in normal individuals at rest, were studied among the 581 respondents tested on two or more occasions. Since all three ventilation variables were significantly correlated with age and weight within this population, the preferred procedure for estimating their effect on the FUCO was to regress the difference between the first and second FUCO (dFUco) on the corresponding differences ( $d \dot{V} E, d V T, d R R$ ) in the ventilation variables. A multiple regression technique was used. The effect of change over time was removed by incorporation of a variable dt, the time between the first and second measurements of the FUco. The mean time difference was 16.6 months, the minimum and maximum possible differences were 6 months and 5 years, and the modal difference 12 months.

Of the three ventilation variables $d V T$ was most highly correlated with dFUco after correction for dt ; neither $d \dot{V} E$ nor dRR contributed significantly when $\frac{0}{\circ}$ added to the regression of dFUco on dt and dVT. While the addition of $\mathrm{dVT}$ to the regression was highly significant $(P<0.01)$, it explained only $1.5 \%$ O of the variance of dFUCo. As the variance of dFUco $\omega$ is related to the variability of repeated measurements $\overrightarrow{0}$ on the same subjects, rather than to the variability $\vec{\overrightarrow{ }}$ of the FUCO among individuals, this implies that very little of the individual variability in FUco measurements is due to individual variability in resting ventilation.

The FUco declines with increasing tidal volume; ir the estimated regression coefficient of dFUco on dVT may be used to correct a measured FUco to $a_{0}$ constant tidal volume. The remainder of these analyses are based on the FUCo corrected to a tidal $\vec{c}$ volume of 0.51 . BTPS by addition of the term $\frac{\mathbb{D}}{O}$ $-0.123654 \times(0.5-\mathrm{VT})$. The correction is minor: $\frac{\overrightarrow{\mathbb{D}}}{7}$ as the mean tidal volume is 0.421 ., the mean correction $\frac{\partial}{0}$ is approximately -0.01 .

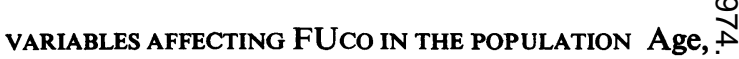
standing height, weight, race, and smoking habit variables were tested for their effect on the FUco, again using multiple regression techniques. Age was, $\frac{\partial}{\circ}$ of course, highly significant $(P<0.001)$ and accounted for $17 \cdot 5 \%$ of the total sums of squares. Standing $\frac{}{\varnothing}$ height, while significantly correlated with the FUCo in a simple regression $(\mathrm{P}<0.05)$, was found to $\frac{0}{3}$ account for only one-third as much of the variance as weight; after correction for weight, standing height was no longer significantly correlated with the FUco. Weight, on the other hand, contributes significantly $(\mathrm{P}<0.05)$ to the prediction of the $\mathrm{FUCO}$ even after the effects of age, race, and smoking habits (which are correlated with weight) are re-3.

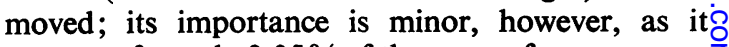
accounts for only $\mathbf{0 . 3 5 \%}$ of the sums of squares.

The effect of race, a higher FUco in Negroes byo 0.0023 , was marginal $(0.05<P<0.10)$ but has been retained in this analysis. The interaction term race $\times$ 으․ age did not approach significance, indicating no racial difference in the decline of the FUCo with age.

Seven smoking categories were defined: three of cigarette smokers, less than 15,15 to 24 , and 25 plus Nల cigarettes per day; nonsmokers; exsmokers; current pipe and/or cigar smokers; and mixed smokers (both cigarettes and pipes and/or cigars). A dummy variable (taking the value 1 if the respondent belonged to that smoking category, 0 otherwise) was assigned to each of these categories except the nonsmokers. These six dummy variables were added to the equation and as a group were very highly significant $(\mathrm{P}<0.001) \frac{\mathrm{P}}{\mathrm{D}}$ Then the set of interaction terms of each with age was added and also found to be significant. These two 
T A B L E I

PREDICTION EQUATION FOR FRACTIONAL CARBON MONOXIDE UPTAKE

\begin{tabular}{|c|c|c|}
\hline Independent Variables & $\mathbf{B x}$ & Bxx $\mathbf{A g}_{\mathbf{g}}$ \\
\hline $\begin{array}{l}\text { Age } \\
\text { Weight (kg) } \\
\text { Race Negro } \\
\text { Ex-smoker } \\
\text { Pipe/cigar smoker } \\
\text { Cigarette smoker }<15 / \text { day } \\
\quad 15-24 / \text { day } \\
\quad 25+/ \text { day } \\
\text { Pipe/cigar and cigarette smoker } \\
\text { Intercept }\end{array}$ & $\begin{array}{r}-0.00204 \\
+0.00040 \\
+0.00230 \\
+0.02413 \\
+0.11588 \\
+0.09130 \\
+0.03466 \\
+0.06053 \\
-0.02686 \\
0.57046\end{array}$ & $\begin{array}{l}\bar{Z} \\
-0.00097 \\
-0.00265 \\
-0.00236 \\
-0.00125 \\
-0.00233 \\
-0.00034 \\
=\end{array}$ \\
\hline
\end{tabular}

$\mathbf{B X}=$ regression coefficient; $\mathbf{B X \times A _ { g e }}=$ regression coefficient on independent variable times age. Race and smoking variables equal 1 i respondent belongs in that category, 0 otherwise. $N=913$. Statistical significance discussed in text.

T A B L E I I

PREDICTED VALUES FOR FRACTIONAL CARBON MONOXIDE UPTAKE IN NON-SMOKERS AND ADDITIVE

\begin{tabular}{|c|c|c|c|}
\hline \multirow[b]{2}{*}{ Smoking Category } & \multirow[b]{2}{*}{$\mathbf{N}$} & \multicolumn{2}{|c|}{ Predicted FUco at Age } \\
\hline & & $30 \mathrm{yr}$ & $60 \mathrm{yr}$ \\
\hline Non-smokers & 121 & 0.537 & 0.476 \\
\hline $\begin{array}{c}\text { Ex-smokers } \\
\text { Pipe/cigar smokers } \\
\text { Cigarette smokers }<15 / \text { day } \\
15-24 / \text { day } \\
25+/ \text { day } \\
\text { Pipe/cigar and cigarette smokers }\end{array}$ & $\begin{array}{r}171 \\
121 \\
65 \\
194 \\
208 \\
33\end{array}$ & $\begin{array}{l}-\overline{0} . \overline{0} \\
+0.036 \\
+0.021 \\
=0.003 \\
=0.009 \\
-0.037\end{array}$ & $\begin{array}{l}-\overline{0} . \overline{034} \\
-0.043 \\
-0.050 \\
-0.040 \\
-0.079 \\
-0.047\end{array}$ \\
\hline
\end{tabular}

For Caucasians, weight $71 \mathrm{~kg}$, tidal volume $0.51 . ;$ add +0.010 to correct predicted values to population mean tidal volume.

sets of variables together account for $5.4 \%$ of the total sums of squares; due to their interdependence their contributions should not be separated.

The final regression coefficients may be seen in Table I. The smoking effects are more readily apparent, however, in Table II which gives the expected FUCO at ages 30 and 60 for nonsmokers and the additive effects of smoking at those two ages. Clearly, there is little difference between smokers and nonsmokers at age 30 and there is even a tendency for light smokers to have higher values than nonsmokers at that age. Rates of decline with age are greater, even doubled, among smokers, however, and by age 60 their FUcos are distinctly lower, by approximately $10 \%$, than those of nonsmokers.

VARIABILITY OF FUCO The standard deviation of the

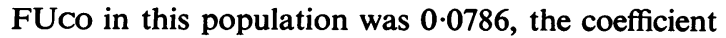
of variation $16.5 \%$. Of more interest, the standard error of estimate about the regression was 0.0693 . Assuming that individual variability was equal on the first two tests, and that the 581 individuals with two tests were reasonably representative of the entire tested population of 913 , the standard deviation of an individual's measurement could be estimated at
T A B L E I I I

DISTRIBUTION OF STANDARDIZED RESIDUALS FROM REGRESSION OF FRACTIONAL CARBON MONOXIDE UPTAKE

\begin{tabular}{c|cc}
\hline & \multicolumn{2}{|c}{ Residuals } \\
\cline { 2 - 3 } Standard Errors of Estimate & No. Expected & No. Observed \\
\hline$<-2.00$ & 20.8 & 19 \\
$-2.00--1.50$ & 40.2 & 29 \\
$-1.50--1.00$ & 83.9 & 79 \\
$-1.00--0.50$ & 136.8 & 134 \\
$-0.50--0.00$ & 174.8 & 224 \\
$+0.00-+0.50$ & 174.8 & 178 \\
$+0.50-+1.00$ & 136.8 & 123 \\
$+1.00-+1.50$ & 83.9 & 58 \\
$+1.50-+2.00$ & 40.2 & 36 \\
$>+2.00$ & 20.8 & 33 \\
& & \\
\hline
\end{tabular}

Residuals are differences between observed FUcos and those expected according to regression equation given in Table $I$, divided by 0.0693 the standard error of estimate. Expected distribution is Normal, with mean 0 and SD 1. $\chi^{2}$ test of goodness of fit significant at the 0.001 level. $\mathrm{N}=913$.

$0 \cdot 0690$. This, of course, refers to individual variability over a period of one to two years.

It was only in the writing of this report that the close similarity between the population standard error of estimate and the individual variability was noted. The implication was that there was almost no variability among individuals remaining to be accounted for; a population standard error of $\sim 0.01$ is implied. Reanalysis of existing results on the 581 respondents with two measurements yielded an estimated population standard error of 0.035 ; removal of the effect of age reduced this to 0.023 ; assuming that the effect of race, weight, and smoking habits were equally important relative to the age effect in these 581 persons as in the total population of 913, the population standard error can be reduced to approximately 0.018 . These values are still extremely small relative to the mean.

A test of the normality of the distribution of the residuals about the regression was carried out. A $\chi^{2}$ value of $43.62(15 \mathrm{df}, P<0.001)$ indicated that the residuals are not normally distributed. A somewhat collapsed distribution is shown in Table III; a large excess of small negative deviates is seen. In view of the small population standard error this distribution is primarily determined by the shape of the distribution of values about the individual means.

The deviation from normality in the distribution is statistically significant, but not extreme, and should not affect the estimates here of means and regression coefficients; significance levels and variance estimates might be slightly affected.

EFFECTS OF POPULATION SAMPLING SCHEME ON RESULTS As described above, this sample had been stratified in a very complex manner (Densen et al., 1965). Numerous multiple regression equations, including as 
independent variables all factors and all the interactions of those factors utilized in the sampling procedure, were carried out. The predicted values for nonsmokers in Table II were found to be changed by less than \pm 0.002 , and no significant changes in the estimated smoking effects were found. What might be somewhat inflated are the proportions of the variance accounted for by the age and smoking history variables in the regression analysis.

\section{DISCUSSION}

Bates (1952) reported measurements of the fractional $\mathrm{CO}$ uptake in normal subjects and in patients with emphysema. Since that time a number of authors have reported on the use of the FUco in the evaluation of respiratory patients (Marks, Cugell, Cadigan, and Gaensler, 1957; MacNamara, Prime, and Sinclair, 1959; Bates, Woolf, and Paul, 1962; Kreukniet and Visser, 1962; Woolf, 1964; Woolf, 1965; Bates et al., 1966; James and Rumble, 1967; Rasmussen and Nelson, 1971; Bates, 1973).

Mean values of the FUco for small numbers of normal subjects have been published by several authors (Bates, 1952; Marks et al., 1957; Shephard, Carey, and Phair, 1958; MacNamara et al., 1959; Woolf, 1964; Woolf, 1965). Mean values of the FUco during exercise for 298 normal women have been published by Woolf and Suero (1971). Aguzzi, Woolf, and Paterson (1966) have reported on the FUco in very old people.

Predicted normal values for the FUco as a function of age and height have been published by Bates $\mathrm{et}$ al. (1971). A prediction equation for white males has been published by Bates et al. (1962): it is FUCO= 0.82085-0.00341 $\times$ age $-0.00322 \times$ height (inches). The prediction equation for white males, based on nonsmokers, from this study is $\mathrm{FUCO}=0.58032$ $0.00204 \times$ age $+0.0004 \times$ weight (kilograms) without correction for tidal volume.

In this study weight correlated much more strongly with the FUco than did height, and the effect of standing height was not significant after correction for weight. The effects of weight and height in this study were positive, rather than negative, as in the equation above of Bates et al. (1962). Anderson and Shephard (1969) found weight to be the most useful anthropometric predictor of single-breath diffusing capacity, and theirs appears to be the only study of diffusing capacity in which the optimum index of body size has been arrived at statistically rather than chosen arbitrarily. The effect of weight on the FUco, although statistically significant, is certainly not strong (Table I).

The effect of race, although again statistically significant, is both minor (Table I) and constant; no indication of a racial difference in decline of the FUco with age comparable to that observed fote the $\mathrm{FEV}_{1}$ in this population (Stebbings, 1973) waș seen, but the analysis of the FUco data may have been too unsophisticated to detect such an effect.

That the FUco should decline with age is no $\vec{b}$ surprising; nor is it surprising that the rate of declinewith age increases with increasing tobacco con sumption. The effect of these variables on the decline of the pulmonary diffusing capacity in population studies has been thoroughly reviewed by Van Ganse Ferris, and Cotes (1972). Reduction of the FUco during exercise among smokers has been reported for both men (Rasmussen and Nelson, 1971) and womero (Woolf and Suero, 1971).

Bates et al. (1971) emphasize the sensitivity of thes FUco to differences in minute volume; Lacoste and Rouch (1965) emphasize the effect of respirator $\vec{D}$ frequency. In this study of normal subjects at rese् minute volume, tidal volume, and respiratory frequency explained only $1.5 \%$ of the individuate variability in the FUCo, and this contribution may in practice be ascribed to the tidal volume alone (Obviously, if individual variability over muclp shorter time periods is studied, the percentage cons tribution of these variables would be higher. Correction of the FUco to any constant tidas volume within the normal testing range is simple; the correction is small but should be used in epidemioe logical studies or when observed values are on the borderline of abnormality.

One of the most interesting findings of this study was that the individual variability of a subject's FUc尺्ष्ठ (over a period of one to two years) was much greate than the unexplained variability in the population: This is the opposite of the situation with lung volumes and flow rates (Stebbings, 1971). Here the standard error of the individual measurement was estimated as approximately 0.07 ; the population standard errob was estimated to be in the range 0.01 to 0.02 .

The standard deviation of the FUco in this population was generally comparable to that reportef. by others (MacNamara et al., 1959; Woolf, 1964) However, Bates (1973) has estimated the standard error of the individual FUco determination to be in the range $0.025-0.04$. These estimates refer, though $h_{0}^{\mathrm{C}}$ to monthly measurements within a year so the timte periods between measurements are much less than the mean 16.6 months in this study.

If the results of this study are valid for measurement of the FUco in large populations, they imply that the FUco is essentially worthless as a screening test foon chronic respiratory disease. The purpose of screening is to detect individuals at high risk of ultimate disability or mortality from chronic respiratory 
disease; a measurement which changes drastically over a period of months, or two or three years, is of little use. What is required is a test which varies among individuals in the population much more than from time to time in the individual, and not the other way around.

However, if changes in an individual's FUco over time truly reflect changes in the state of his lungs then the test might be a sensitive tool for the measurement of short-term effects of environmental factors on the lung.

Bates et al. (1971) express the opinion that the FUco is 'a most useful index of normality'. They claim the major advantage of simplicity of measurement and calculation for the FUco, point out as its main disadvantage sensitivity to minute volume, and suggest that it would be useful in screening for chronic respiratory disease. The simplicity of the procedure is evident, but these data do not fully support their other generalizations. Extrapolation of these findings concerning the fractional carbon monoxide uptake to more sophisticated methods of measuring carbon monoxide exchange I shall leave to others.

I wish to thank Dr. Paul M. Densen, Mrs. Ellen Jones, and Dr. Hyman E. Bass for allowing and encouraging me to continue analysis of these data.

The work was supported by the National Institute for Occupational Safety and Health of the United States Public Health Service through grants $\mathrm{OH}-00013$ and EC-00233 to the Medical and Health Research Association of New York City and grant OH-00353 to the University of Minnesota.

\section{REFERENCES}

Aguzzi, G., Woolf, C. R., and Paterson, J. F. (1966). The prevalence and type of chronic obstructive bronchopulmonary disease in very old people. Canadian Medical Association Journal, 94, 932.

Anderson, T. W. and Shephard, R. J. (1968). The effects of hyperventilation and exercise upon the pulmonary diffusing capacity. Respiration, $25,465$.

- and - (1969). Normal values for the single-breath diffusing capacity-The influence of age, body size and smoking habits. Respiration, $26,1$.

Bates, D. V. (1952). The uptake of carbon monoxide in health and in emphysema. Clinical Science, 11, 21.

(1973). The fate of the chronic bronchitic: a report of the ten-year follow-up in the Canadian Department of Veteran's Affairs coordinated study of chronic bronchitis. The J. Burns Amberson Lecture of the American Thoracic Society. American Review of Respiratory Diseases, 108, 1043.

, Gordon, C. A., Paul, G. I., Place, R. E. G., Snidal, D. P., and Woolf, C. R. (1966). Chronic bronchitis. Report on the third and fourth stages of the coordinated study of chronic bronchitis in the Department of Veterans Affairs, Canada. Medical Services Journal of Canada, 22, 5.
—, Macklem, P. T., and Christie, R. V. (1971). Respiratory Function in Disease, 2nd edition. W. B. Saunders, Philadelphia, London, and Toronto.

Woolf, C. R., and Paul, G. I. (1962). Chronic bronchitis. A report on the first two stages of the co-ordinated study of chronic bronchitis in the Department of Veterans Affairs, Canada. Medical Services Journal of Canada, 18, 211.

Densen, P. M., Jones, E. W., and Bass, H. E. (1965). Respiratory symptoms and tests among New York postmen. Archives of Environmental Health, 10, 370.

$-, \ldots,-$, and Breuer, J. (1967). A survey of respiratory disease among New York City postal and transit workers. I. Prevalence of symptoms. Environmental Research, 1, 265.

,,,$--- \ldots$, and Reed, E. (1969). A survey of respiratory disease among New York City postal and transit workers. II. Ventilatory function test results. Environmental Research, 2, 277.

James, F. and Rumble, Jr, L. (1967). Carbon monoxide diffusing studies in the clinical evaluation of chronic lung diseases. Diseases of the Chest, 52, 387.

Kreukniet, J. and Visser, B. F. (1962). CO-diffusing capacity, fractional CO-uptake and unequal ventilation. Acta Physiologica et Pharmacologica Neerlandica, 11, 386.

Lacoste, J. (1971). Exploration fonctionnelle respiratoire. $\mathrm{La}$ ductance DuCO (monoxyde de carbone): évaluation globale, non sanglante, de l'échangeur pulmonaire. La Presse Médicale, 79, 1781.

- (1972). Etude des echanges et de l'échangeur pulmonaire: les ductances partielles et globales. Bulletin de Physio-Pathologie Respiratoire, 8, 146.

— and Rouch, Y. (1965). Influence de la fréquence ventilatoire sur le transfert du $\mathrm{CO}$ en état stable. Comptes Rendus de la Société de Biologie de Nancy, 159, 208.

MacNamara, J., Prime, F. J., and Sinclair, J. D. (1959). An assessment of the steady-state carbon monoxide method of estimating pulmonary diffusing capacity. Thorax, 14, 166.

Marks, A., Cugell, D. W., Cadigan, J. B., and Gaensler, E. A. (1957). Clinical determination of the diffusion capacity of the lungs. American Journal of Medicine, 22, 51 .

Rasmussen, D. L. and Nelson, C. W. (1971). Respiratory function in Southern Appalachian coal miners. American Review of Respiratory Disease, 103, 240.

Shephard, R. J., Carey, G. C. R., and Phair, J. J. (1958). Evaluation of a portable box-bag for field testing of pulmonary diffusion. Journal of Applied Physiology, $12,79$.

Stebbings, Jr, J. H. (1971). Chronic respiratory disease among nonsmokers in Hagerstown, Maryland. II. Problems in the estimation of pulmonary function values in epidemiological surveys. Environmental Research, 4, 163.

(1972). A survey of respiratory disease among New York City postal and transit workers. III. Anthropometric, smoking, occupational, and ethnic variables affecting the $\mathrm{FEV}_{1}$ among white males. Environmental Research, 5, 451. 
(1973). A survey of respiratory disease among New York City postal and transit workers. IV. Racial

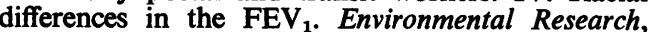
$6,147$.

Van Ganse, W. F., Ferris, Jr, B. G., and Cotes, J. E• (1972). Cigarette smoking and pulmonary diffusing capacity (transfer factor). American Review of Respiratory Disease, 105, 30.

Woolf, C. R. (1964). An assessment of the fractional carbon monoxide uptake and its relationship to pulmonary diffusing capacity. Diseases of the Chest, 46, 181.
- (1965). The relationships between minute ventilation pulmonary gas diffusion and respiratory work measured simultaneously during a standard exercise test. Diseases of the Chest, 47, 616.

— and Suero, J. T. (1971). The respiratory effects of regular cigarette smoking in women. American. Review of Respiratory Disease, 103, 26.

Requests for reprints to: Dr. J. H. Stebbings, Mayø్టు Memorial Building, Box 197, School of Public Health University of Minnesota, Minneapolis, Minnesotax 55455, U.S.A. 